\title{
The Effects of Vincristine and Doxorubicin on the Clonogenic Cells of a Human Lung Cancer Cell Line in Methylcellulose and Suspension Culture
}

\author{
Yoko Yamashita, Nobuo Nara and Nobuo Aoki \\ First Department of Internal Medicine, Tokyo Medical and Dental University, 5-45, Yushima 1-chome, \\ Bunkyo-ku, Tokyo 113
}

\begin{abstract}
The effects of vincristine (VCR) and doxorubicin (DOX) on the growth of an established line of human lung cancer cells, PC9, were studied in methylcellulose and suspension cultures. The secondary colony formation in methylcellulose and recovery of clonogenic cells in suspension were considered to reflect well the self-renewal of the clonogenic cells. When dose-response curves were obtained for VCR and DOX, the primary clonogenic cells (PE1) were more sensitive than secondary clonogenic cells (PE2) or clonogenic cells in suspension. Repeated exposure to VCR in suspension did not inhibit the exponential growth of the clonogenic cells. These data indicated that both drugs were relatively ineffective in specifically suppressing the self-renewal of the clonogenic cells.
\end{abstract}

Key words: Lung cancer cell line PC9 - Colony assay - Suspension culture - Vincristine Doxorubicin

A progressive accumulation of tumor cells in malignancies has been considered to be supported by a small subpopulation, tumor stem cells; tumor stem cells renew themselves and also undergo terminal divisions, providing many progenies. Therefore, the goal of chemotherapy for malignancies may be the eradication of tumor stem cells. To predict the effectiveness of antitumor agents, chemosensitivity tests have been developed using tumor clonogenic assay. However, previous studies on the relationship between in vitro and in vivo effects in tumor clonogenic assays testing drug sensitivities have reported high true-negative results but comparatively lower true-positive rates. ${ }^{1-3)}$ They indicate the difficulties of achieving the clinical elimination of the malignant clones. This problem may be approached by seeking other cell culture methods having a better relationship with the cell proliferative kinetics in vivo.

In acute myeloblastic leukemia (AML), blast progenitors form colonies in methylcellulose and can be easily dispersed in the medium into a single cell suspension for pooling and replating to form secondary colonies. In the present study, the terms PE1 and PE2 will be used to describe the primary and secondary clonogenic cells, respectively. Blast progenitors grow exponentially in suspension. ${ }^{4)}$ PE1 is considered to reflect the terminal divisions of the blast progenitors, while PE2 and the recovery of clonogenic cells in suspension are considered to reflect the self-renewal. ${ }^{4-8)}$ Self-renewal is the biological nature of blast progenitors; secondary colony-forming ability has been shown to correlate highly with the clinical outcome. ${ }^{6}$ Chemosensitivity tests for AML have been carried out in methylcellulose and suspension cultures. ${ }^{9-15)}$ The sensitivity of blast progenitors in methylcellulose is not necessarily correlated with the outcome. In contrast, a good correlation between drug sensitivity in suspension and clinical effects has been noted. ${ }^{10)}$ These findings imply that the effects of drugs on self-renewal might be most important. It is of interest to apply the same theory to tumor stem cells of other human malignancies and to examine the effects of antitumor drugs especially on the self-renewal of tumor stem cells. ${ }^{16)}$ Drugs that are effective against the self-renewal of tumor cells would be expected to be efficacious in the clinical setting.

The purpose of this study was to establish a method for screening of the effects of antitumor drugs using a cancer cell line. Although a question still remains as to whether the clonogenic cells of an established cell line are equivalent to freshly obtained tumor cells, their high proliferative property is representative of the self-renewal phenomenon of the tumor stem cells. In this light, we considered it appropriate to utilize such a cell line as a model for tumor stem cells.

In the present study, we studied and compared the effects of vincristine (VCR) and doxorubicin (DOX) on the human lung cancer cell line PC9, both in clonogenic assay and in suspension culture. Both drugs were dosedependently effective in growth inhibition, but to a greater degree for PE1 than for PE2 or clonogenic cells in suspension culture, suggesting that the drugs are relatively ineffective in inhibiting the self-renewal of tumor cells.

\section{MATERIALS AND METHODS}

Cell line PC9 was established from human adenocarcinoma of the lung by Dr. Hayata at Tokyo Medical College. It has been propagated in RPMI-1640 medium (GIBCO, Grand Island, N.Y.) with $10 \%$ fetal 
calf serum (FCS, GIBCO), at $37^{\circ} \mathrm{C}$ in $5 \% \mathrm{CO}_{2}$ in a humidified incubator. ${ }^{17,18)}$ The cells grew in small floating aggregates which could easily be disaggregated by pipetting gently.

Clonogenic assay in methylcellulose culture Tumor cells were plated at the concentration of 5 to $10 \times 10^{3} / \mathrm{ml}$ in a Lux Petri dish (Miles Lab., Naperville, Ill.) in $1 \mathrm{ml}$ of RPMI-1640 medium with $0.8 \%$ methylcellulose (4000 cps, Wako Co., Osaka) and $15 \%$ FCS. Cultures were incubated at $37^{\circ} \mathrm{C}$ in humidified air containing $5 \% \mathrm{CO}_{2}$. Colonies of more than 40 cells were counted under a microscope after 7 days. These primary clonogenic cells were described as PE1. The primary colonies were diluted with medium, pipetted gently to form a single cell suspension, pooled, washed twice in medium, and then replated at a concentration of $10^{4} / \mathrm{ml}$ in Linbro microwells (Flow Lab., McLean, Va.) in $0.1 \mathrm{ml}$ of RPMI-1640 with $0.8 \%$ methylcellulose and $15 \% \mathrm{FCS}$, and incubated likewise. Secondary colonies of more than 40 cells were counted after 7 days. The secondary clonogenic cells were designated as PE2. Several colonies of both primary and secondary cultures were collected, stained and observed under a microscope to ascertain the similarity in morphology. Single colony assay was also done: a single primary colony was picked up with a fine micro-pipette under a microscope and replated in $0.1 \mathrm{ml}$ of RPMI-1640 with $0.8 \%$ methylcellulose and $15 \%$ FCS, together with $10^{4} / \mathrm{ml}$ autologous irradiated ( $20 \mathrm{~Gy}$ ) cells. Fifty colonies were picked up and secondary colony-forming ability from each single colony was determined.

Suspension culture PC9 cells were cultured at the concentration of $2 \times 10^{4} / \mathrm{ml}$ in a Lux Petri dish in $3 \mathrm{ml}$ of RPMI- 1640 with $15 \%$ FCS by the modified method of Nara and McCulloch. ${ }^{4)}$ At intervals, cells were harvested, counted and either used for clonogenic assay in methylcellulose or subcultured in a new suspension. The recovery of clonogenic cells was determined by multiplying the plating efficiency in methylcellulose by the number of harvested cells per dish from suspension.

Drug sensitivity tests VCR or DOX was added continuously to the culture at various concentrations. In methylcellulose, the number of primary colonies was determined after 7 days of incubation with various concentrations of the drugs. The colonies formed at each concentration were pooled, washed three times in RPMI1640 and after adjustment for cell number, replated for secondary colony assay without drugs. As for suspension culture, cells were harvested after 7 days of exposure to various concentrations of VCR or DOX, counted, washed three times and used for clonogenic assay in methylcellulose without drugs.

Statistics Data are shown as the mean \pm SD of triplicate cultures. The dose-response curves for the drugs were determined by linear regression analysis. The dose required to reduce survival to $10 \%$ of the control (D10) was calculated from the negative exponential curves.

\section{RESULTS}

Growth patterns of PC9 cells A statistically significant linear relationship was seen between the number of cells plated and colonies formed per dish, supporting the existence of clonogenic cells $(P<0.01$, Fig. 1). The actual numbers of primary and secondary colonies formed were $966.89 \pm 180.4 / 10^{4}$ and $151.7 \pm 40.7 / 10^{3}$, respectively.

Primary PC9 colonies were pooled, washed and replated into methylcellulose for up to 8 weeks. Plating efficiency did not change, and the self-renewing capacity was maintained in methylcellulose.

Single colonies were picked up and replated to examine the self-renewal of each clonogenic cell. Figure 2 shows the distribution of secondary colony-forming ability from single primary colonies; the distribution was heterogeneous among the clonogenic cells, and some showed no such ability.

Figure 3 shows the result of short-term culture of PC9 cells in suspension. The clonogenic cells grew exponentially up to 7 days, and degenerated thereafter. Meanwhile, secondary clonogenic cells were maintained until day 9 when the cells had begun to degenerate and the number of cells harvested was too small for PE2

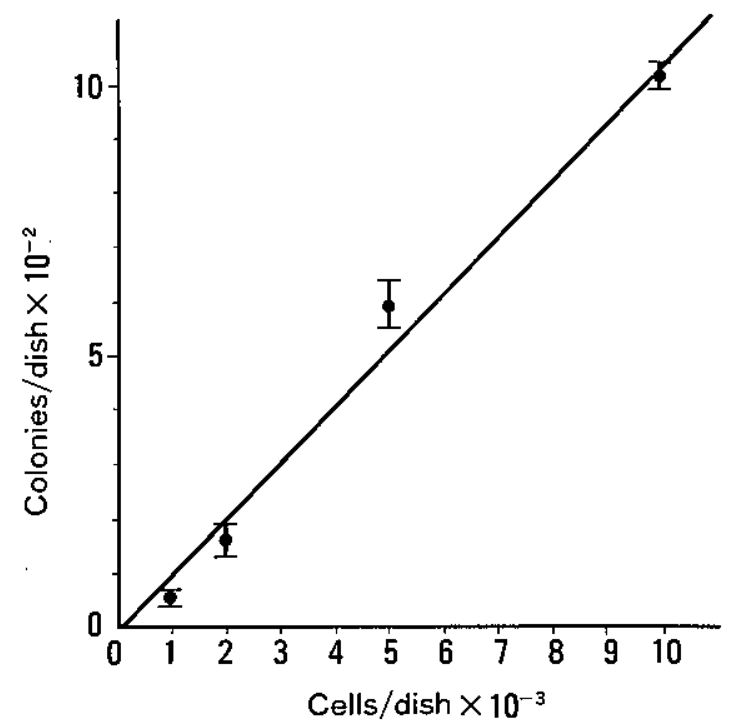

Fig. 1. The relationship between the input number of PC9 cells and colonies counted after 7 days' culture in methylcellulose. A statistically significant linear relationship is seen $(r=0.992 ; P<0.01)$. Data are shown as the mean $\pm \mathrm{SD}$ of triplicate plates. 


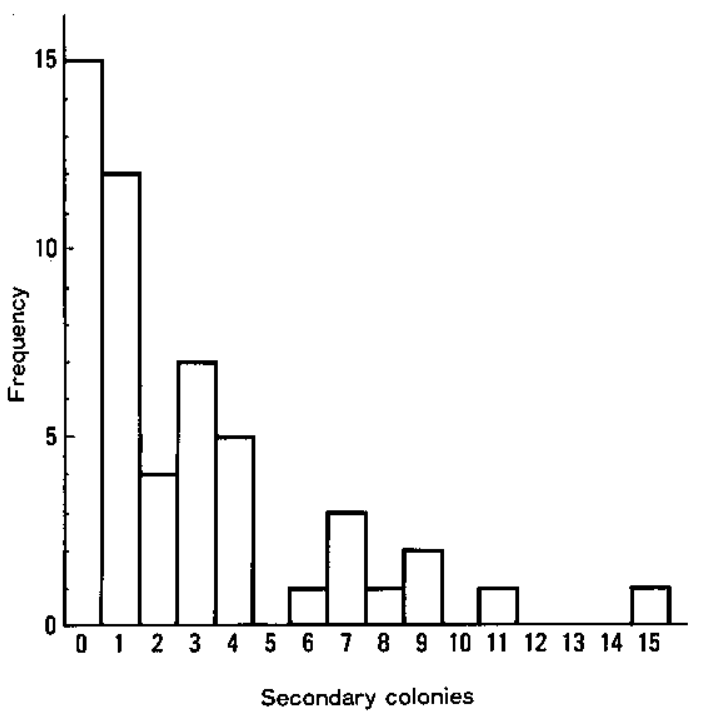

Fig. 2. The distributions of the frequency of secondary colony formation among single colonies. The numbers on the $\mathrm{X}$ axis show the number of secondary colonies yielded by replating each single colony, and the $\mathrm{Y}$ axis shows the corresponding frequencies. Fifty primary colonies were analyzed. This experiment was repeated twice with similar results.

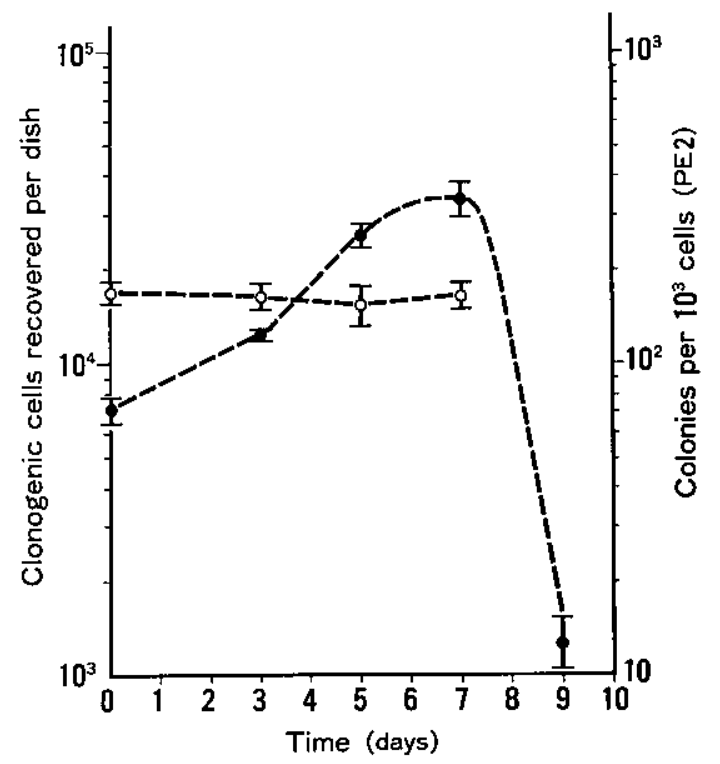

Fig. 3. Clonogenic cells recovered per dish after suspension culture from day 0 to 9 . The number of clonogenic cells ( $\bullet$ was obtained by multiplying the number of cells harvested at each time point by the number of colonies yielded after 7 days' culture in methylcellulose. These colonies were further pooled and replated to determine the secondary colony-forming abilities (O) except for day 9, when the cells were degenerated. assay. The cells in suspension were subcultured in a new medium and also used for clonogenic assay on every 7 th day, when the cells showed maximal growth. Figure 4 shows the cumulative growth curve of the clonogenic cells per dish for as long as 98 days, calculated from the dilution at each subculture. During this time clonogenic cells increased exponentially. Clonogenic cells continued to grow after day 98 (data not shown).

Effect of VCR on PC9 VCR was added at various concentrations to both methylcellulose and suspension cultures. Figure 5 shows the dose-response curves of VCR for PE1 and PE2 in methylcellulose and the recovery of clonogenic cells in suspension culture. All three showed simple negative exponential curves. The D10 values for PE1, PE2 and clonogenic cells in suspension were $7.4 \mathrm{ng} / \mathrm{ml}, 32.5 \mathrm{ng} / \mathrm{ml}$, and $40.4 \mathrm{ng} / \mathrm{ml}$, respectively. It is apparent that the D10 value is the greatest for suspension culture.

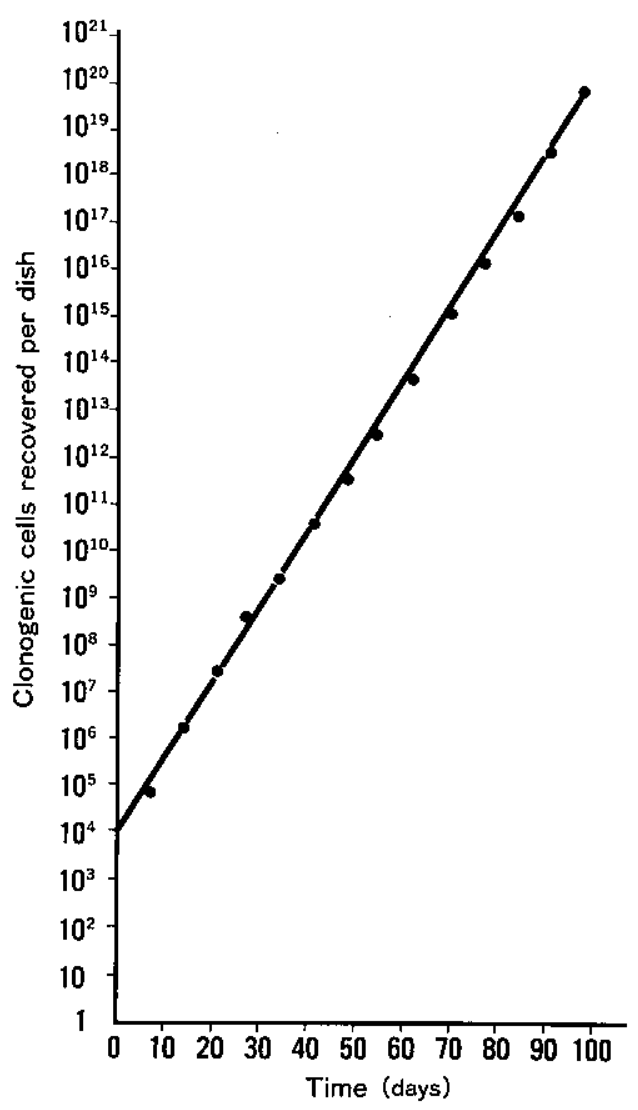

Fig. 4. A cumulative growth curve of the clonogenic cells per dish, when cells were subcultured in suspension every 6 to 8 days. A statistically significant exponential growth is observed ( $r=0.999 ; P<0.01$ ). 


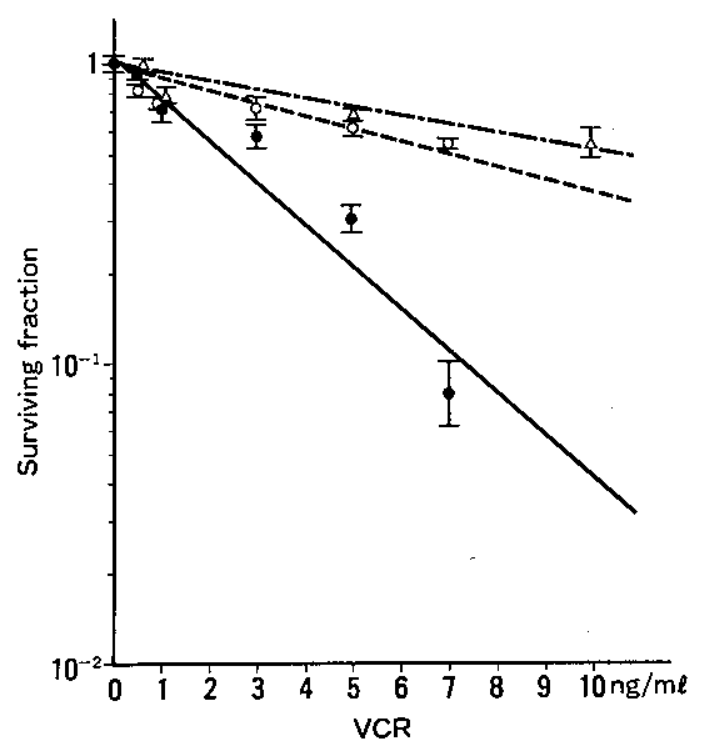

Fig. 5. VCR survival curves for PC9 cells in methylcellulose (PE1: - PE2: $O$ ) and suspension $(\triangle)$. The curves are negative exponentials (PE1: $r=0.955, P<0.01$; PE2: $r=0.916, P<$ 0.05 , suspension: $r=0.943, P<0.05$ ).

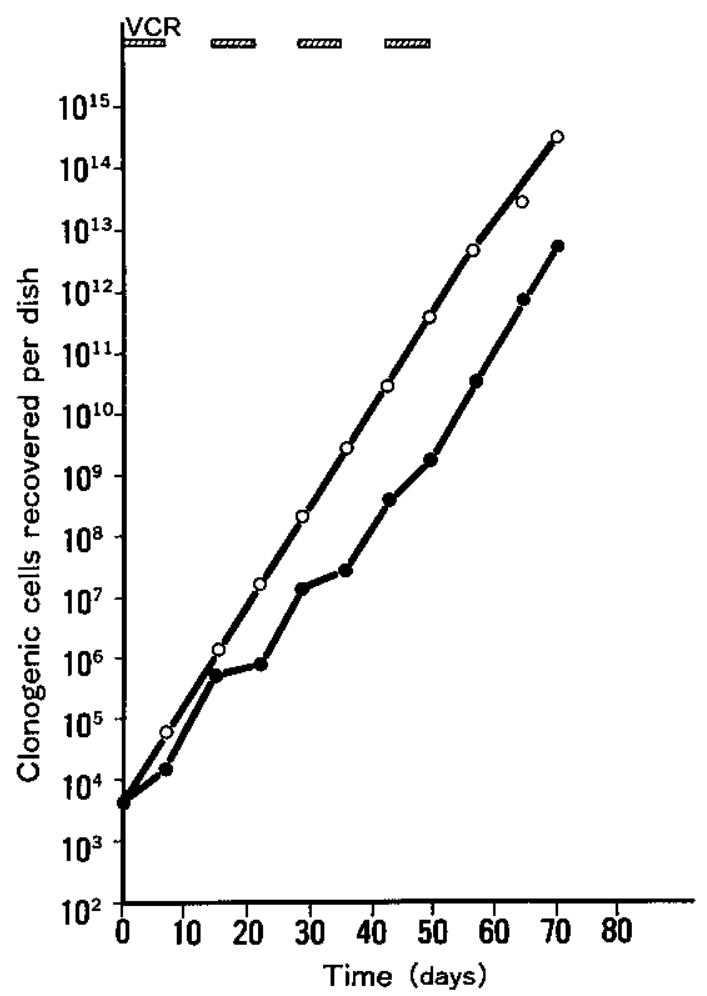

Fig. 6. Cumulative growth curves of the clonogenic cells with repeated exposure during prolonged culture in suspension. Control cultures are shown as $\bigcirc$. Cells ( $\bullet$ ) were exposed to VCR $(40 \mathrm{ng} / \mathrm{ml}$ ) every other week as shown at the top of the figure.
Repeated exposure to VCR Figure 6 shows the effect of repeated exposure of PC9 cells to VCR at $40 \mathrm{ng} / \mathrm{ml}$, a dose near the D10 value in the suspension, added to every other subculture for one week. The cells were then harvested, washed and recultured without drug for another week, or used for clonogenic assay. This drug exposure schedule was repeated 4 times. Compared with the control cultures, growth of clonogenic cells was inhibited following each exposure and exponential growth resumed after the cessation of exposure in the next subculture. It appeared from this growth curve that the degree of inhibition decreased as drug exposure was repeated. This was verified by determining the $\mathrm{D} 10$ value of the cells after 4 drug exposures; the D10 values for PE1 and PE2 were $28.4 \mathrm{ng} / \mathrm{ml}$ and $41.6 \mathrm{ng} / \mathrm{ml}$, respectively. The changes in the values probably indicate that the cells had grown somewhat resistant to the drug.

Effect of DOX on PC9 cells Dose-response curves are also shown for PE1, PE2 and clonogenic cells in suspension with various concentrations of DOX in Fig. 7. These form simple negative exponential curves, the D10 values being $24 \mathrm{ng} / \mathrm{ml}, 53 \mathrm{ng} / \mathrm{ml}$, and $86 \mathrm{ng} / \mathrm{ml}$, respectively. PE1 was more sensitive to DOX compared with PE2 or clonogenic cells in suspension.

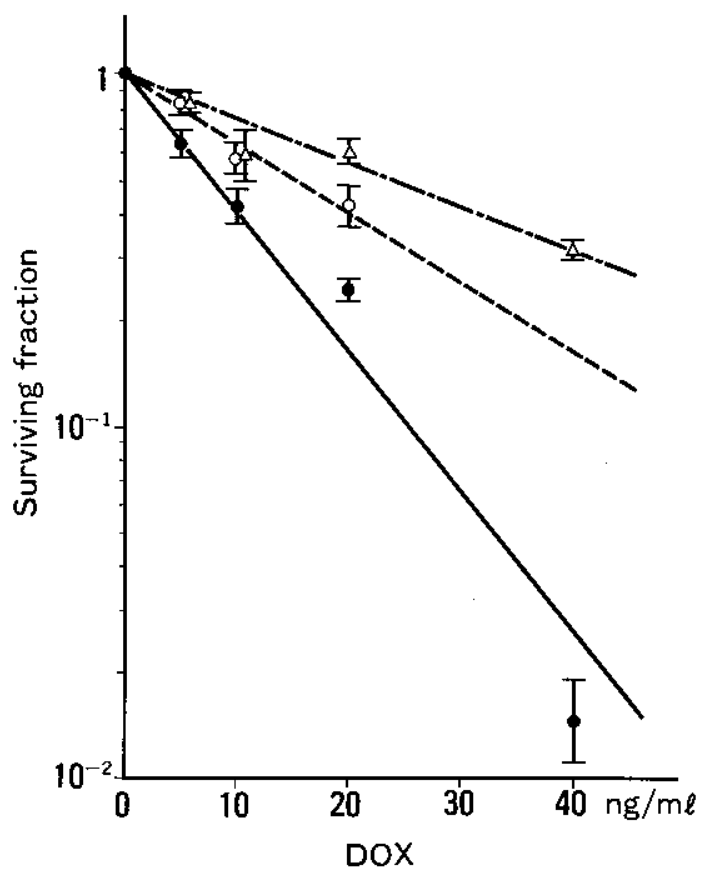

Fig. 7. DOX survival curves for cells in methylcellulose (PE1: -, PE2: $O$ ) and suspension $(\triangle)$. These form simple negative exponential curves (PE1: $r=0.985, P<0.01$; PE2: $r=0.987$, $P<0.05$; suspension: $r=0.961, P<0.01)$. 


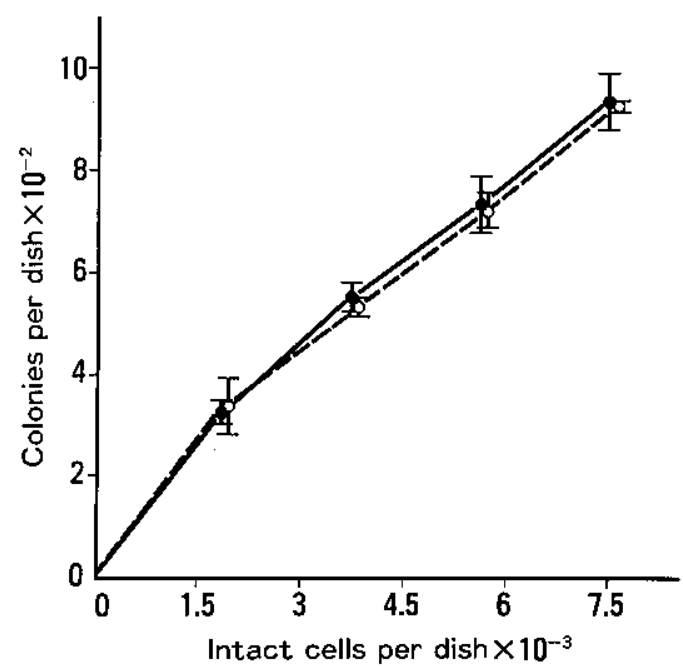

Fig. 8. Drug carry-over control. Cells were exposed to VCR $(20 \mathrm{ng} / \mathrm{ml})$ for 7 days in suspension, then recovered, washed and irradiated $(20 \mathrm{~Gy})$. These were added to intact cells in methylcellulose to provide a fixed cell number. The relationship between the number of input intact cells and the colonies yielded for VCR-treated $(\bullet)$ and nontreated $(O)$ cells is shown.

Drug carry-over control In the suspension culture procedure, the cells incubated with various amounts of drugs for 7 days are harvested, washed and replated in methylcellulose. To exclude the possibility that the drug may be carried over into the methylcellulose culture, the following control study was done. The PC9 cells were exposed to VCR for 7 days in suspension, then recovered, washed and irradiated ( $20 \mathrm{~Gy}$ ) to destroy their proliferating ability. These cells were plated in methylcellulose with various numbers of intact PC9 cells to fix the total number of cells per dish. The number of colonies formed was counted and compared with those in cultures of irradiated control cells which had not been exposed to the drug. From Fig. 8 it is evident that there is no significant difference between the VCR-treated and nontreated cells.

\section{DISCUSSION}

For the screening of drug activity against tumor stem cells, a practical system to detect the effects of the drugs primarily on the self-renewal capacity of the cells is required. This study was designed to examine the techniques of clonogenic assay and suspension culture, in the light of previous studies on leukemia as a manifestation of self-renewal. ${ }^{10-12)}$ On the basis of those reports, drugs can be grouped according to their functional characters: 1) 1- $\beta$-D-arabinofuranosylcytosine as dec reasing, 2) DOX and other anthracyclines as not affecting, and 3) 5-azacytidine as increasing the self-renewal of blast progenitors. ${ }^{14)}$ Since VCR is a widely used drug for malignancies, it was selected for study, in comparison with DOX as a control.

Although studies on fresh tumor cells may be most reliable, they take a long time and there are difficulties in obtaining suitable samples or in screening a large number of drugs. The use of a cell line may be one way to overcome such problems. Studies on the growth pattern of PC9 cells indicated that the repeated colony formation after replating and the exponential growth of the clonogenic cells in a long-term suspension (Fig. 4) reflected high self-renewal characteristics. When single primary colonies were picked up and tested for secondary colony-forming abilities, a marked heterogeneity was observed in the frequency distribution (Fig. 2), but heterogeneity in the proliferative abilities may be insufficient to prove the existence of terminal division cells within the cell population. It may be more appropriate to consider that highly proliferative clones have been dominant during the propagation and thus have maintained the cell line. In this case the question remains as to whether PE1 individually represent terminal division cells, as is generally believed for blast progenitors of AML, but we have shown that PE2 and the increase of clonogenic cells in suspension reflect the behavior of self-renewing cells. This may be of relevance to the self-renewing subpopulation of fresh tumor cells, and thus we consider that PC9 cells would be a useful model for screening of drug effects on human tumor stem cells.

The D10 values determined from the dose-response curves of VCR were greater for PE2 and suspension compared with PE1. The difference of D10 values between PE1 and suspension could not be explained by drug carry-over from the suspension into methylcellulose, as shown in Fig. 8. One of the possibilities is that the two culture systems have different underlying populations functioning, ${ }^{5,6)}$ while another may be a difference in time for recovery from drug toxicity between the culture systems. Whatever the reason, the D10 values for PE2 and suspension were much larger than the standard dose $(1 \mathrm{ng} / \mathrm{ml})$, which is generally considered to be about one-tenth of the peak plasma concentration, based on pharmacologically achievable concentration. This pattern was comparable to that of DOX. The two drugs possibly belong to the same category (Figs. 5 and 7), since both at the standard dosage were relatively ineffective on the self-renewal of the tumor cells.

In suspension cultures, the cell growth recovery can be studied at various intervals after drug treatment. Another advantage of suspension culture is that the tumor cells can be maintained for a long period so that the effects of 
repeated drug exposure can be studied, imitating the actual protocols of anti-neoplastic chemotherapy (Fig. 6 ). The results showed that exposure every other week to a dose near D10 of VCR in suspension was only temporarily effective against the self-renewal of PC9 cells. It is possible that other schedules of drug exposure may result in different effects.

For the screening of currently used or newly developed anti-tumor drugs, it is necessary to detect the drugs effective against the self-renewal of tumor stem cells. Such assays as studied in the present report should also be tried on freshly obtained human materials to examine

\section{REFERENCES}

1) Kanzawa, F., Hoshi, A., Shimizu, E., Saijo, N., Miyazawa, N. and Shimabukuro, Z. Clonogenic cell assay for carcinoma of the lung. Gann, 75, 81-88 (1984).

2) Von Hoff, D. D., Clark, G. M., Stogdill, B. J. Sarosdy, M. F., O'Brien, M. T., Casper, J. T., Mattox, D. E., Page, C. P., Cruz, A. B. and Sandbach, J. F. Prospective clinical trial of a human tumor cloning system. Cancer Res., 43, 1926-1931 (1983).

3) Weisenthal, L. M. Clonogenic and non clonogenic in vitro chemosensitivity assays. Cancer Treat. Rep., 69, 615-632 (1985).

4) Nara, N. and McCulloch, E. A. The proliferation in suspension of the progenitors of the blast cells in acute myeloblastic leukemia. Blood, 65, 1484-1493 (1985).

5) Buick, R. N., Till, J. E. and McCulloch, E. A. Colony assay for proliferative blast cells circulating in myeloblastic leukemia. Lancet, 1, 862-863 (1977).

6) Buick, R. N., Minden, M. D. and McCulloch, E. A. Self-renewal in culture of proliferative blast progenitors in acute myeloblastic leukemia. Blood, 54, 95-104 (1979).

7) Mackillop, W. J., Ciampi, A., Till, J. E. and Buick, R. N. A stem cell model of human tumor growth: implications for tumor cell clonogenic assays. J. Natl. Cancer Inst., 70, 9-13 (1983).

8) McCulloch, E. A. and Till, J. E. Blast cells in acute myeloblastic leukemia. A model. Blood Cells, 7, 63-77 (1981).

9) McCulloch, E. A. Experimental approaches to outcome prediction in acute myeloblastic leukemia. Recent Results Cancer Res., 94, 76-92 (1984).

10) Nara, N., Curtis, J. E., Senn, J. S., Tritchler, D. I. and McCulloch, E. A. The sensitivity to cytosine arabinoside of the blast progenitors of acute myeloblastic leukemia. Blood, 67, 762-769 (1986). the relationship between the in vitro sensitivity and the clinical outcome.

\section{ACKNOWLEDGMENTS}

We wish to thank Dr. Kanzawa of the National Cancer Center for providing the cell line PC9, and Dr. Matsubara of the Department of Radiology, Tokyo Medical and Dental University, for his kind cooperation in the irradiation experiments.

(Received October 8, 1988/Accepted January 10, 1989)
11) Nara, N., Yamashita, Y., Murohashi, I., Tanikawa, S., Imai, Y. and Aoki, N. The effects on blast progenitors from murine myeloblastic leukemia of $1-\beta-\mathrm{D}$-arabinofuranosylcytosine and anthracyclines adriamycin, daunomycin, aclacinomycin-A, and 4'-epidoxorubicin. Cancer Res., 47, 2376-2379 (1987).

12) Wang, C. and McCulloch, E. A. Sensitivity to 5azacytidine of blast progenitors in acute myeloblastic leukemia. Blood, 69, 553-559 (1987).

13) Yamashita, Y. Nara, N., Murohashi, I., Imai, Y. and Aoki, N. Comparative effects of vinca alkaloids (VCR, VDS) and epipodophyllotoxin (VP16) on murine myeloblastic leukaemia. Br. J. Cancer, 55, 517-519 (1987).

14) Nara, N., Suzuki, T., Yamashita, Y., Murohashi, I. and Aoki, N. Cytotoxicity of 4-hydroxycyclophosphamide for the blast progenitors of acute myeloblastic leukemia. Cancer Res., 48, 2348-2352 (1988).

15) Nara, N., Suzuki, T., Yamashita, Y., Murohashi, I. and Adachi, Y. Relationship between the in vitro sensitivity to cytosine arabinoside of blast progenitors and the outcome of treatment in acute myeloblastic leukaemia patients. $\mathrm{Br}$. J. Haematol., 70, 187-191 (1988).

16) Buick, R. N. and Mackillop, W. J. Measurement of self-renewal in culture of clonogenic cells from human ovarian carcinoma. Br. J. Cancer, 44, 349-355 (1981).

17) Lee, Y-C., Saijo, N., Sasaki, Y., Takahashi, H., Sakurai, M., Ishihara, J., Sano, T., Hoshi, A., Chen, K-M. and Hamburger, A. W. Antitumor effect of two-drug simultaneous or sequential use of cisplatin, vindesine or etoposide on human pulmonary adenocarcinoma cell lines in tumor clonogenic assay. Jpn. J. Cancer Res., 77, 312-318 (1986).

18) Kinjo, M., Oka, K., Kohga, S. and Yasumoto, K. Thromboplastic and fibrinolytic activities of cultured human cancer cell lines. Br. J. Cancer, 39, 15-23 (1987). 